doi: $10.2306 /$ scienceasia1513-1874.2013.39.520

\title{
Changes in friction, surface roughness, and tensile strength upon compaction of Ficus deltoidea powder
}

\author{
T.C. Ooi ${ }^{\mathrm{a}}$, Y.A. Yusof ${ }^{\mathrm{a}, *}$, N.L. Chin ${ }^{\mathrm{a}}$, R.A. Talib ${ }^{\mathrm{a}}$, S.H. Othman ${ }^{\mathrm{a}}$, M.G. Aziz ${ }^{\mathrm{a}, \mathrm{b}}$ \\ a Department of Process and Food Engineering, Faculty of Engineering, Universiti Putra Malaysia, 43400, \\ Serdang, Selangor, Malaysia \\ b Department of Food Technology and Rural Industries, Bangladesh Agricultural University, \\ Mymensingh-2202, Bangladesh
}

*Corresponding author, e-mail: niza@eng.upm.edu.my

Received 27 Jul 2012

Accepted 12 May 2013

\begin{abstract}
The study is concerned with the quantitative measurement of changes in friction, surface roughness, and tensile strength during the compaction of Ficus deltoidea powder, a well-known Malaysian herb. In the compaction process, the force applied for compaction (upper punch) was greatly influenced by the friction between die wall and powder bed during transmission to the lower punch. Wall friction was found to increase with the increasing load and weight of powder due to an increase in surface contact with the die wall. The coefficients of wall friction decreased from 0.47 to 0.36 for increasing weight of powder from 0.8-1.5 g. Tablets with a higher compaction load of $9.5 \mathrm{kN}$ had a lower arithmetic mean deviation $\left(R_{\mathrm{a}}\right)$, an indicator of surface roughness. $R_{\mathrm{a}}$ for the top surface is lower than that of for the bottom surface.
\end{abstract}

KEYWORDS: herbs, compressibility, tablet, uniaxial die, Kawakita equation

\section{INTRODUCTION}

F. deltoidea herb is one of the famous traditional herbs in Malaysia. This herb is found rich in flavonoid, tannin, triterpenoid, and phenolic compounds and it has long tradition in treating gout, hypertension, and diabetes as well as improving blood circulation and reducing cholesterol and toxin in the body. Due to the health benefit, $F$. deltoidea herb powder is frequently compressed to make it easy and convenient to use as a medication $^{1}$.

During compaction, a force is applied to a powder bed in the die and is arranged in a closer packing structure to preserve its ingredients. Overall compaction of a powder involved particle rearrangement, elastic deformation of particles, plastic deformation, and fragmentation of particles and formation of inter particulate bonds ${ }^{2,3}$. Nevertheless, the friction phenomenon is one of the most important factors that occurred during the material deformation during the powder forming process. Contact friction is among the most difficult nonlinear problem since the response in contact interface is not smooth ${ }^{4}$. The friction force between the die and compacts is an active pressing force to reduce the density gradient. Frictional forces at the die wall severely impede powder movement, which is seen as a force loss from the top to the bottom punch ${ }^{5}$.
Variation in surface roughness of a compressed tablets surface also occurs due to wall friction and super smoother surface is considered as a quality machined piece. There are several simple methods to inspect a surface, including visual inspection with the naked eye or feeling with the bare fingers ${ }^{6}$. The effects of surface roughness on friction coefficients are studied quantitatively to develop a better understanding of frictional properties ${ }^{7}$. In the case of $A n$ drographis paniculata herb, compaction characteristic has been discussed in relation to wall friction and surface roughness using an indirect method. During compression, as the increasing amount of compressed powder, the tensile strength is increased, and from the surface roughness test, the coefficient of wall friction and angle of wall friction are decreased ${ }^{8}$. In this study the changes in wall friction and surface roughness phenomenon and their relationship with the compaction of $F$. deltoidea herbs were studied and discussed.

\section{MATERIALS AND METHODS}

\section{Herb and its properties}

F. deltoidea powder used in this study was purchased from Ya'acob Berkat Enterprise, Malacca. Before compaction, material properties of powder like moisture content, density, and particle size and shape were 

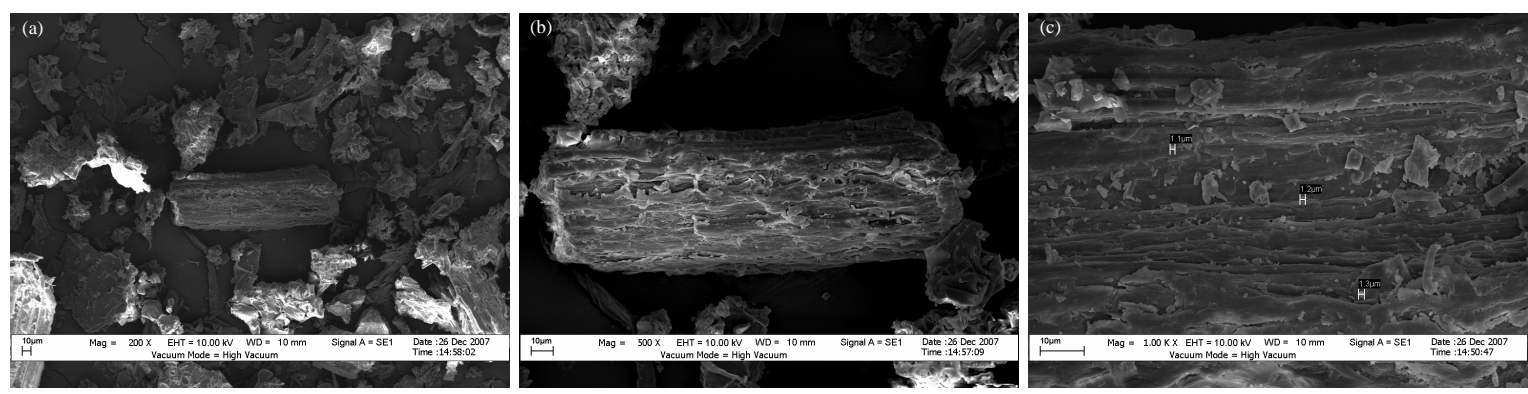

Fig. 1 SEM images of $F$. deltoidea: (a) $200 \times$, (b) $500 \times$, (c) $1000 \times$.

Table 1 Material properties of F. deltoidea herbs.

\begin{tabular}{lc}
\hline Material Properties & F. deltoidea powder \\
\hline Bulk Density $\left(\mathrm{kg} / \mathrm{m}^{3}\right)$ & 242.66 \\
Tapped Density $\left(\mathrm{kg} / \mathrm{m}^{3}\right)$ & 316.59 \\
Moisture Content $($ Oven $)(\%)$ & 10.11 \\
Moisture Content (Digital) $(\%)$ & 10.28 \\
Carr Index $(\%)^{9}$ & 23.35 \\
Hausner Ratio & 1.3 \\
Flowability & Poor flowability \\
Mean particle size, $D_{50}(\mu \mathrm{m})$ & $80-180$ \\
\hline
\end{tabular}

determined by the methods reported by Yusof et $\mathrm{al}^{1}$ (Table 1). The particle size and shape of $F$. deltoidea herbs were visually evaluated by the Scanning Electronic Microscope (SEM) and shown in Fig. 1.

\section{Uniaxial compaction of tablet}

The tablets were uniaxially compacted by using a cylindrical $20 \pm 0.1 \mathrm{~mm}$ diameter hardened stainless steel (Fig. 2a). The compactions were carried out by using a universal testing machine (Instron Universal Testing Machine 5566, Canton MA, USA). The powder mass ranging from 0.8 to $1.5 \mathrm{~g}$ were compacted to various ultimate applied stresses in the dies. The powder of each tablet was weighted by using a digital balance with accuracy range of $\pm 0.001 \mathrm{~g}$. The applied force and the cross-head displacement were recorded by computer software. All tablets were compacted by an ultimate force ranging between 5 and $9.5 \mathrm{kN}$. The compaction of powder was done by according to the method as described by Yusof et $\mathrm{al}^{8}$. The force displacement curve, ejection pressure, and tensile strength were recorded by Merlin software. The procedure was followed by unloading and removal of bottom punch, and then the tablet was ejected from the die. Fig. $2 b$ shows arrangement of the die for the ejection process, whereby the bottom punch was removed and force was applied using the universal testing machine. Tissue paper was placed at
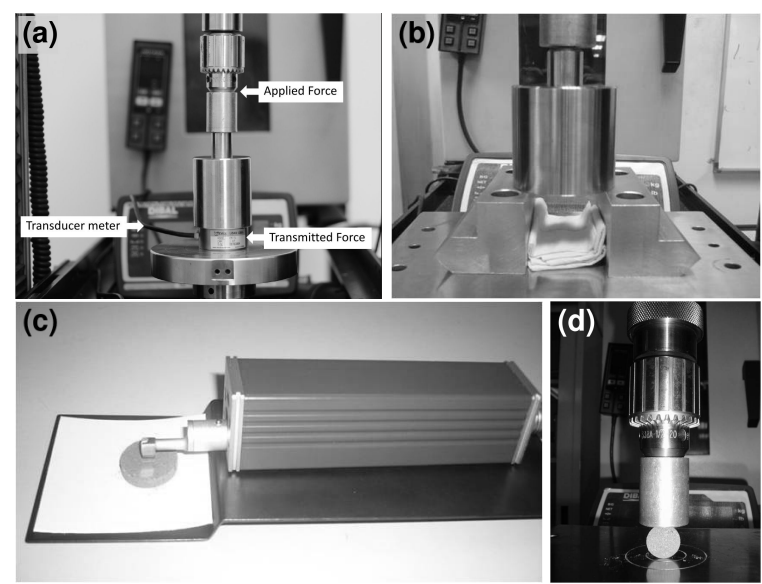

Fig. 2 Pictures of (a) compaction process, (b) set-up for an ejection process, (c) surface roughness test, and (d) tensile strength test of the tablet produced.

the bottom to serve as a cushion for the ejected tablet.

\section{Die wall friction properties}

The compact-die wall frictional effects associated with the aspect ratio (compact height/diameter ratio) were studied by ejecting several compacts of varying mass. By using Janssen-Walker differential slice analysis, the mean radial stress normal to the die wall imparted during compaction was estimated. The stress relaxation upon unloading was ignored and the average powder die wall friction coefficient during ejection was calculated using the following equation ${ }^{11}$ :

$$
\ln \frac{\sigma_{\mathrm{b}}}{\sigma_{\mathrm{a}}}=-4 \mu K_{\mathrm{w}} F_{\mathrm{D}}\left(\frac{H}{D}\right),
$$

where $\sigma_{\mathrm{b}}$ is the transmitted stress, $\sigma_{\mathrm{a}}$ is the applied stress, $\mu$ is the coefficient of die wall friction, $K_{\mathrm{w}}$ is a constant, equal to $0.4, F_{\mathrm{D}}$ is a constant, equal to $1.0, H$ is final height of compaction and $D$ is compact diameter. 
Besides that, loads on the upper and lower cells were measured by applying force $F_{\mathrm{a}}$ on the upper piston and the transmitted force $F_{\mathrm{t}}$ on the lower piston, respectively. The wall friction $F_{\mathrm{w}}$ during powder compaction can be determined from the applied force $F_{\mathrm{a}}$ and the transmitted force $F_{\mathrm{t}}$ using the equation ${ }^{11}$ :

$$
F_{\mathrm{w}}=F_{\mathrm{a}}-F_{\mathrm{t}} .
$$

\section{Surface roughness test}

Roughness is usually measured as a sum of negative and positive deviations from a 'mean plane' fit over the surface of interest. Typical parameter for roughness is defined with the equation ${ }^{6}$ :

$$
R_{\mathrm{a}}=\frac{1}{L} \int_{0}^{L}|y(x)| \mathrm{d} x,
$$

where $R_{\mathrm{a}}$ is the arithmetic average surface roughness, or average deviation, $y$ is the height of the surface above the mean line at distance $x$ from the origin, and $L$ is the overall length of the profile under examination. A surface roughness tester (Mitutoyo SJ-201, Japan) was used to compare the surface roughness values of top and bottom surfaces of the tablets (Fig. 2c). The surface roughness value will be displayed automatically within a few seconds. Then, the surface roughness of $F$. deltoidea herbal tablet were visually evaluated by an atomic force microscope (Q-Scope250, USA).

\section{Tensile strength upon compaction of tablets}

The tensile strength of the tablets can be explained using the principles of fracture mechanics ${ }^{12}$. It depends upon the internal distribution of flaws and cracks as well as the same features on the surface. The tensile strength of the tablets was determined according to the method of Fell and Newton ${ }^{13}$ :

$$
\sigma_{\mathrm{s}}=\frac{2 F_{\mathrm{s}}}{\pi D t}
$$

where $F_{\mathrm{s}}$ is the tensile force $(\mathrm{N}), D$ is the diameter of the tablet (m) and $t$ is the height of the tablet (m).

This is an indirect method of measuring tensile strength of soft and fluffy powders, which has been widely used in the pharmaceutical industry. In the literature, this test is also called as a Brazilian test or diametrical compression test.

The tensile strength of the compacted samples or in the current context the compressive strength was determined by using the universal testing machine (Instron Universal Testing Machine 5566, Canton MA, USA) with the maximum allowable load of $1 \mathrm{kN}$.
In this test, the tablets were placed on the side and crushed uniaxially as shown in Fig. 2d until an ideal tensile failure occurs ${ }^{13}$. Tensile failure was observed for all the cylindrical compacts when compressed between flat faces platens ${ }^{13}$.

\section{Compressibility of powder}

The equations that commonly used to assess the compressibility of powder are the Heckel and Kawakita equation as these equations are able to relate to the physical properties of the materials are being compacted. The powder metallurgy area tends to use the Heckel equation, whereas Kawakita holds best for soft fluffy pharmaceutical powders and stated that particular attention must be paid to the measurement ${ }^{14}$. The Kawakita and Lüdde equation ${ }^{15}$ in the linear interrelationship is shown as below:

$$
\frac{P}{C}=\frac{1}{a b}+\frac{P}{a},
$$

where $P$ is the applied pressure, constant $a$ is equal to the porosity of the powder bed prior to compression, constant $b$ is a measure of the ease with which volume reduction of the powder bed occurs. $C$ is the relative volume decrease:

$$
C=\frac{V_{0}-V}{V_{0}},
$$

where $V_{0}$ is the initial volume of the powder bed and $V$ is the powder volume after compression.

\section{RESULTS}

\section{The effects of the die wall friction upon compaction}

The Janssen-Walker ${ }^{16}$ analysis was adopted to evaluate the friction coefficient under conditions similar to the compaction process. The applied compaction pressure to transmit the pressure against the aspect ratio $(H / D)$ for different weight of $F$. deltoidea herbs was plotted to obtain the coefficient of wall friction, $\mu$. The coefficient of wall friction, $\mu$, and the angle of wall friction, $\varphi_{\mathrm{w}}$, were calculated from the slope of the graph (Fig. 3). The calculated value of $\mu$ was 0.47 for $0.8 \mathrm{~g}$ of compacted powder, which was based upon the friction between the powder and the stainless steel die wall. The angle of wall friction $\varphi_{\mathrm{w}}$ calculated using (1) was $25.38^{\circ}$. The values of $\mu$ for the 1.0 and $1.5 \mathrm{~g}$ of F. deltoidea powder were 0.43 and 0.36 , respectively. The angles of wall friction $\varphi_{\mathrm{w}}$ were $23.39^{\circ}$ and $19.77^{\circ}$ as given in Table 2. The frictions decreased from 0.47 to 0.36 as the weight of compact increased. This is similar to the results from previous study by Yusof 


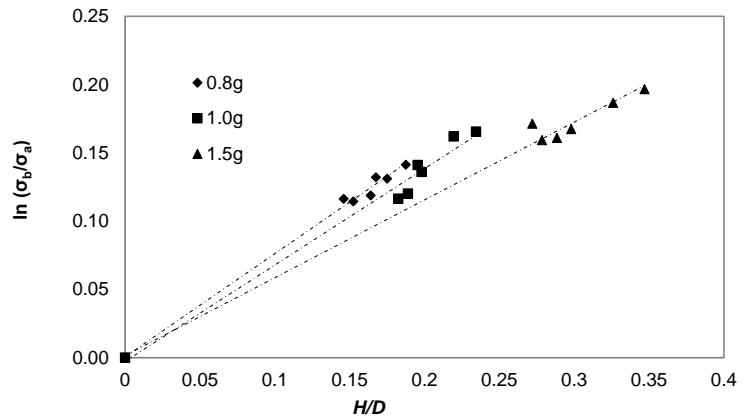

Fig. 3 Applied compaction pressure to transmitted pressure as a function of the initial bed height to diameter ratio for different weight of $F$. deltoidea herbs.

Table 2 The calculated coefficient of the wall friction, $\mu$ and angle of wall friction, $\varphi_{\mathrm{w}}$ by using the graph plotted based on the Janssen-Walker equation for different weights of herbs.

\begin{tabular}{lccc}
\hline Weight & $\mu$ & $\varphi_{\mathrm{w}}$ & $R^{2}$ \\
\hline $0.8 \mathrm{~g}$ & 0.47 & 25.38 & 0.993 \\
$1.0 \mathrm{~g}$ & 0.43 & 23.39 & 0.981 \\
$1.5 \mathrm{~g}$ & 0.36 & 19.77 & 0.989 \\
\hline
\end{tabular}

et $\mathrm{al}^{8}$ using Andrographis paniculata herbs compacted from 5 to $9.5 \mathrm{kN}$.

The friction between the powder bed and the die wall plays an important role during the processing of powder compacts. The force $F_{\mathrm{t}}$ transmitted to the lower punch was less than the applied force $F_{\text {a }}$ due to friction between the powder and the die wall $F_{\mathrm{w}}$. The wall friction force was almost proportional to the applied compaction force (Fig. 4). Fig. 4 demonstrated that the wall fiction increased as the compaction load increased. By comparing the wall friction with different weight, it illustrated that the higher weight gave the higher wall friction. The wall

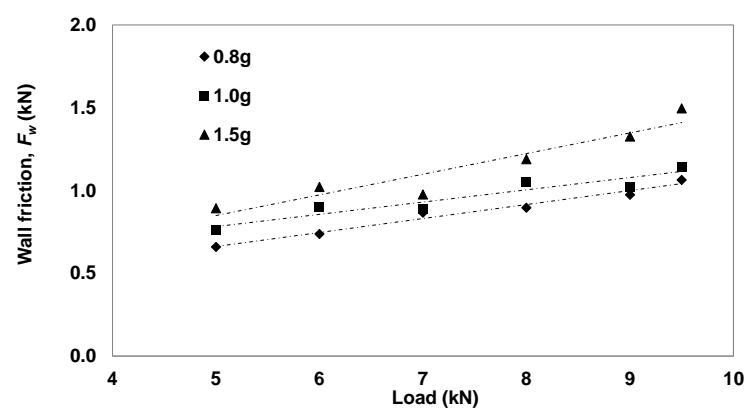

Fig. 4 Wall friction force againts applied compaction load for different weights of $F$. deltoidea herbs.
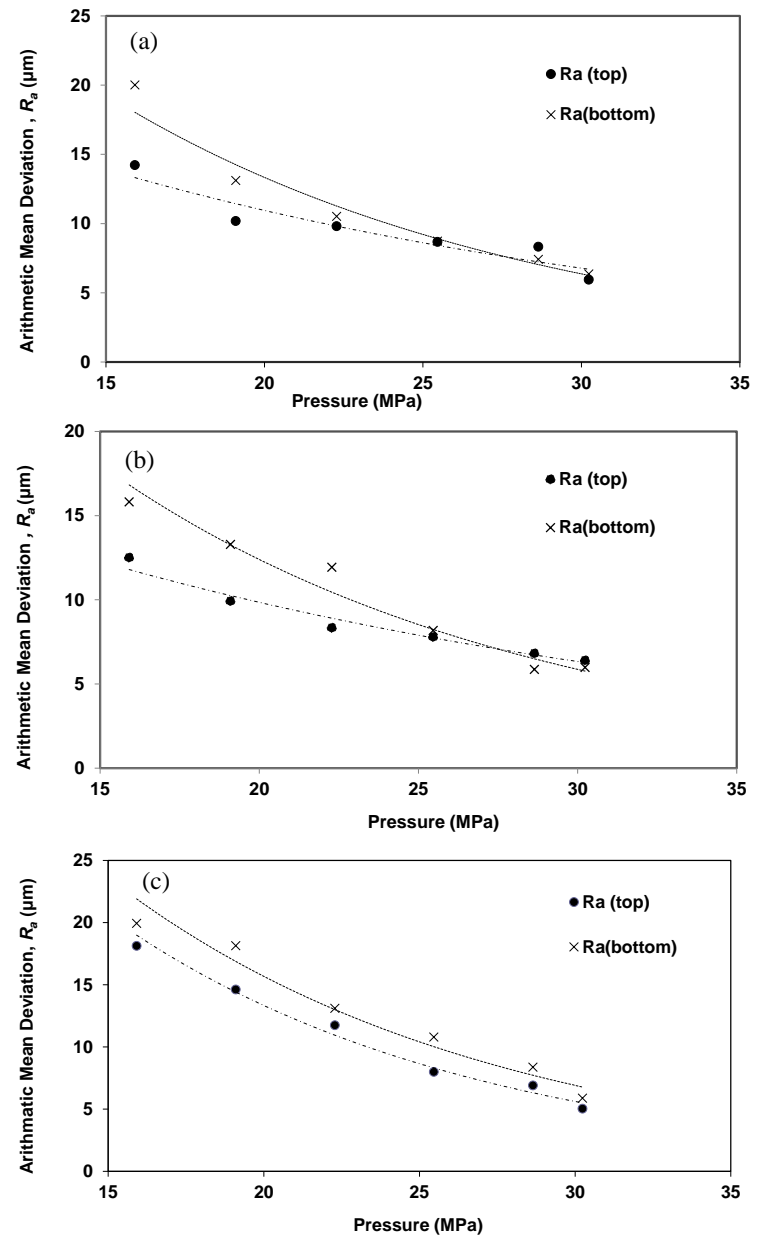

Fig. 5 Arithmetic mean deviation versus compaction pressure at different weights of $F$. deltoidea (a) $0.8 \mathrm{~g}$ (b) $1.0 \mathrm{~g}$ (c) $1.5 \mathrm{~g}$. The lines are the trend lines.

friction increased with an increase in friction area. For the weight powder $1.5 \mathrm{~g}$ with the compaction load $9.5 \mathrm{kN}$, the wall friction was as high as $1.496 \mathrm{kN}$.

\section{The effects of the surface roughness upon compaction}

The observations were performed with a surface roughness tester to study the structure and surface roughness in contact mode with the tablets. All the measurements were performed at room temperature by using the JIS B0601-1994 standard. The effective measurement length of tablet is $10 \mathrm{~mm}$ and with cutoff length and sampling at $2.5 \times 3 \mathrm{~mm}$. Fig. 5 indicated the relationship of the arithmetic mean deviation, $R_{\mathrm{a}}$, which decreased as a function of compaction pressure increased for $0.8,1.0$, and $1.5 \mathrm{~g}$ tablets. The figures indicated that the tablets compacted with low 


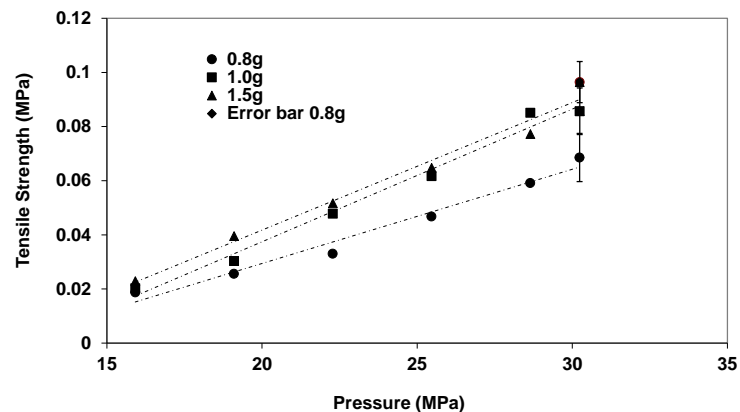

Fig. 6 Tensile strength versus compaction load per unit tablet area at different weights of $F$. deltoidea. Error bars are based upon six measurrements.

compression forces demonstrated high $R_{\mathrm{a}}$. Based on Fig. 5a and Fig. 5b, at the compaction pressure of 28.64 MPa, the $R_{\mathrm{a}}$ for top surface was higher than the $R_{\mathrm{a}}$ at bottom surface.

With further increase of the weight of powder for compaction $(1.5 \mathrm{~g})$, the $R_{\mathrm{a}}$ values did not overlap within the pressure studied (Fig. 5c). Since mean deviation curves are not parallel, further increased of the pressure might result in mean deviation crossed each other.

Surface morphology using atomic force microscopy (AFM) was used to determine the surface roughness profile using compaction load 50 and $100 \mathrm{kN}$. The $R_{\mathrm{a}}$ values obtained were $1.099 \mu \mathrm{m}$ and $0.733 \mu \mathrm{m}$, respectively, at $50 \mathrm{kN}$ and $100 \mathrm{kN}$. The results showed that tablet prepared with higher compaction pressure gave lower $R_{\mathrm{a}}$ values. This study illustrated that $R_{\mathrm{a}}$ decreased with increased compaction pressure. The same observation was reported by Riippi et al ${ }^{17}$, who measured the surface structure of erythromycin acistrate tablets by using AFM. Tablet with low compaction load was fragile and loosed so the surface profile not clearly shown out.

\section{Tensile strength versus compaction}

The tensile strength on the tablets generally increases with increase of applied compaction load. Fig. 6 demonstrated the relationship of the tensile strength to the pressure for different weight of $F$. deltoidea herbs. The tensile strength increased as the weight increased from 0.8 to $1.5 \mathrm{~g}$. As discussed above, the deformation during compaction increased with an increase of applied load. As a result, the bonding between interparticles increased with the highest pressure applied. This is supported by previous study in which higher compression loads resulted in a continuous increase in tensile strength until a certain value was reached ${ }^{18}$.

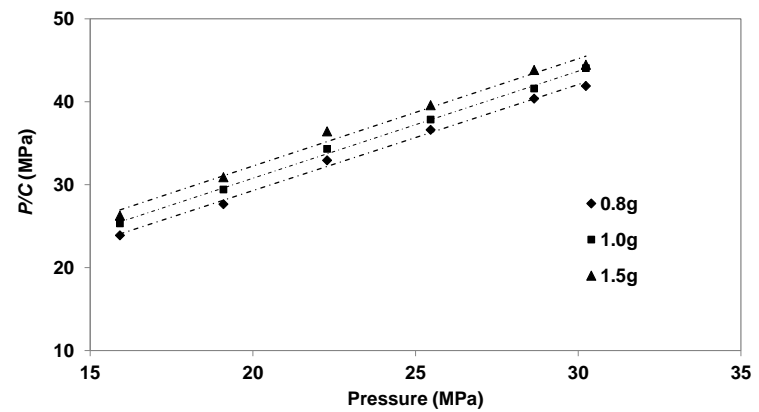

Fig. 7 Compaction data plotted according Kawakita for different weights of $F$. deltoidea. The lines are the trend line.

At low tablet porosities of $0.8 \mathrm{~g}$, a slightly increase in tablet deformation resulted in a remarkable increase in tablet strength. At such low porosities, the interparticle pore system were prepared from the larger tablet. This can be explained by the theory that larger tablet will have higher compactability ${ }^{19}$. The shape and size of pores, particle size, cohesiveness, and moisture content were important criteria in the tablet tensile strength.

\section{The compressibility of the powder}

The Kawakita and Lüdde ${ }^{15}$ equation held best for soft fluffy pharmaceutical powders was studied to describe the early phase of particle rearrangement and compaction for low compaction pressure. Fig. 7 showed the graph of $P / C$ versus $P$. The constants $a$ and $b$ were calculated from the linear fitting of the equation. The constant $a$ represents the initial packing, compressibility and porosity, while $b$ represents the "resistance to compaction" of the material. Hence, $1 / b$ is considered to be related to the cohesive forces of powder particles. According to Fig. 7, $P / C$ increases with increases in both powder weight and compression pressure. It reveals that the pressure exerted due to unit volume change linearly changes with changing pressure but is slightly affected with a change of weight.

Table 3 depicted the value of constants $a$ and $b$ from Kawakita's plot for different weight of powders. It can be observed that the constant $a$ was slightly changed from 0.7819 to 0.7728 whereas constant $b$ was decreased from 0.3467 to 0.2037 .

The compressibility of $0.8 \mathrm{~g}$ F. deltoidea powder was higher than that of 1.0 and $1.5 \mathrm{~g}$. This can be explained by the particle rearrangement and the volume changes. Thereby, the particle sizes of the powder were equalized and thus formed strong inter- 
Table 3 The constant of Kawakita equation for different weights of herbs.

\begin{tabular}{cccc}
\hline Weight & $a$ & $b$ & $R^{2}$ \\
\hline $0.8 \mathrm{~g}$ & 0.7819 & 0.3467 & 0.995 \\
$1.0 \mathrm{~g}$ & 0.7746 & 0.2614 & 0.997 \\
$1.5 \mathrm{~g}$ & 40.7728 & 0.2037 & 0.987 \\
\hline
\end{tabular}

particle bonding. Powder of $1.5 \mathrm{~g}$ shows the lowest compactibility and lowest resistance to flow. Besides that, the smaller value of $1 / b$ is proportional to good flowability and small cohesiveness that have shown by the powder of $0.8 \mathrm{~g}$. This value was compared with previous study by Yusof et $\mathrm{al}^{8}$ on compaction of $F$. deltoidea herbs which gave the similar values.

\section{DISCUSSION}

This study experimentally determines the wall friction, surface roughness, and tensile strength of compacted $F$. deltoidea powder under different powder mass compactions. Three masses of tablets: 0.8, 1.0, and $1.5 \mathrm{~g}$ which are normal oral doses, were tableted in this study. The most popular Janssen-Walker ${ }^{16}$ equation was used to calculate the coefficient of wall friction and the angle of wall friction. The applied stress to the transmitted stress and aspect ratio have been modelled with the equation and from the slope of the curve, coefficient of wall friction has been calculated considering herb powder as a viscoelastic material. The inverse tangent of wall friction was presented as the angle of friction. The lower value of transmitted stress over applied stress manifests the loss of force due to wall friction, and losses of force were more pronounced with increasing loading of powder. The friction between the die wall and the powder bed results in friction force and this is found almost proportional to the applied force (Fig. 4). The herb powder weight is also a great factor for frictional force. This is because the contact between powder and die wall is higher than that of the lower weight of powder. The same observation was found in a previous study, which measured the wall friction and compaction characteristic of bentonite powder at compaction pressure of $70-665 \mathrm{kN}^{20}$.

Concerning the surface roughness, the increase in compaction pressure should make the tablet surface smoother and decrease the roughness of the tablet ${ }^{21}$. The arithmetic mean deviation $\left(R_{\mathrm{a}}\right)$ is usually used as quantitative parameter to measure the surface roughness. It is the sum of negative and positive deviations from a 'mean plane' fit over the surface of interest. For the same weight of powder compacted, the $R_{\mathrm{a}}$ of top surface was found lower than that of bottom surface (Fig. 5). This proved that the force applied from the top resulted in the particle to have better bonding and gave smoother surface. The applied force was lost during transmitting to the lower surface and, hence, $R_{\mathrm{a}}$ of bottom surface gave the higher value. For this reason, the bottom surfaces are rougher than the top surfaces due to the less transmitted pressure than the applied pressure. This phenomenon is also clearly observed by the SEM pictures, which reveal the profile of surface roughness during compaction of herb powder with different loads. This is supported by the previous studies of Özkan and Briscoe ${ }^{20}$, who found that the high compaction pressure, the closured of the inter-agglomerate pore after deformation, and the surface topography of the compacts did not change appreciably. This is because the particle sizes were unequal due to the surface deformation and the original inter-agglomerate pores in the compacts are effectively eliminated at this compaction pressure ${ }^{19}$. The instant relaxation (expansion) of the tablet on the upper surface of the tablets during decompression as the upper punch returns might have restricted the tablet in the bottom to relax. Moreover, during the ejection of the tablets by pushing them from the bottom of the die, the upper surfaces were subjected to lateral deformation or relaxation while leaving the edge of the restricted die wall ${ }^{22}$.

Each tablet should have sufficient resistance against external tensile force encountered during transportation and storage. Tensile strength is also an important parameter that needs to be considered for the dissolution of tablets. Tablets with higher tensile strength might be convenient in terms of resisting external force and they are also durable against dissolution. The increase of tensile strength with increasing compaction pressure and amount of powder indicated that the bonding among the particles were stronger. It is also noticeable that the slope of the force-tensile strength curve also increases with an increase in the amount of powder. It means that the stronger bonding increased the elasticity of the compacted powder and thus required higher strength for failure. It was also evident that the failure strengths linearly changed with applied pressure and tensile strength. However, this linear relationship is up to a certain pressure and it has been found that after $9 \mathrm{kN}$, the behaviour is not predictable. However, the compressibility study indicated that the lower amount of powder exhibited the better compressibility as $b$ went lower with increasing powder weight. The smaller value of $1 / b$ predicts the good flowability and small cohesiveness that have shown by the powder of $0.8 \mathrm{~g}$ (Table 3 ). 
The results presented in this study concerning the wall friction, surface roughness, and tensile strength phenomenon are very helpful to understand the fundamental process of compaction for F. deltoidea herbs concerning the energy utilization during the process. The data reported in this investigation can be used as quantitative measurement of on the limit of the compaction strength of $F$. deltoidea herb powder.

Acknowledgements: The authors acknowledge the Universiti Putra Malaysia for the Research University Grant Scheme granted with project no: 937800 .

\section{REFERENCES}

1. Yusof YA, Abdullah R, Ling CK, Rahman RA (2008) Understanding the tabletting behavior of Ficus deltoidea herb. Pertanika J Sci Tech 16, 15-22.

2. Newton JM (1992) A method of evaluating the mechanical characteristics of powders from the determination of the strength of compacts. Powder Tech 72, 97-9.

3. Mohammed H, Briscoe BJ, Pitt KG (2005) The interrelationship between the compaction behavior and the mechanical strength of pure pharmaceutical tablets. Chem Eng Sci 60, 3941-7.

4. Keshavarz Sh, Khoei AR, Khaloo AR (2008) Contact friction simulation in powder compaction process based on the penalty approach. Mater Des $\mathbf{2 9}$, 1199-211.

5. Briscoe BJ, Evans PD (1991) Wall friction in the compaction of agglomerated ceramic powders. Powder Tech 65, 1-20.

6. Seitavuopio P, Rantanen J, Yliruusi J (2003) Tablet surface characterization by various imaging techniques. Int J Pharm 254, 281-6.

7. Sahin M, Çetinarslan CS, Akata HE (2007) Effect of surface roughness on friction coefficients during upsetting processes for different materials. Mater Des 28, 633-40.

8. Yusof YA, Ng SK, Chin NL, Talib RA (2010) Compaction pressure, wall friction and surface roughness upon compaction strength of Andrographis paniculata tablets. Tribol Int 43, 1168-74.

9. Carr RL (1965) Evaluating flow properties of powders. Chem Eng 72, 163-7.

10. Hausner HH (1967) Friction conditions in a mass of metal powder. Int J Powder Metall 3, 7-13.

11. Briscoe BJ, Rough SL (1998) The effects of wall friction on the ejection of pressed ceramic parts. Powder Tech 99, 228-33.

12. Sriapai T, Walsri C, Fuenkajorn K (2012) Effect of temperature on compressive and tensile strengths of salt. Sci Asia 38, 166-74.

13. Fell JT, Newton JM (1968) Tensile strength of lactose tablets. J Pharm Pharmacol 20, 657-9.

14. Denny PJ (2002) Compaction equations: a comparison of the Heckel and Kawakita equations. Powder Tech 127, 162-72.

15. Kawakita K, Lüdde KH (1971) Some considerations on powder compression equations. Powder Tech 4, 61-8.

16. Briscoe BJ, Evans PD (1991) Wall friction in the compaction of agglomerated ceramic powders. Powder Tech 65, 7-20.

17. Riippi M, Antikainen O, Niskanen T, Yliruusi J (1998) The effect of compression force on surface structure, crushing strength, friability and disintegration time of erythromycin acistrate tablets. Eur J Pharm Biopharm 46, 339-45.

18. Adolfsson $\AA$, Nyström C (1996) Tablet strength, porosity, elasticity and solid state structure of tablets compressed at high loads. Int J Pharm 132, 95-106.

19. Johansson B, Alderborn G (1996) Degree of pellet deformation during compaction and its relationship to the tensile strength of tablets formed of microcrystalline cellulose pellets. Int J Pharm 132, 207-20.

20. Özkan N, Briscoe BJ (1996) The surface topography of compacted agglomerates; a means to optimize compaction conditions. Powder Tech 86, 201-7.

21. Cameron IM, Gethin DT (2001) Exploration of die wall friction for powder compaction using a discrete finite element modeling technique. Model Simulat Mater Sci Eng 9, 289-307.

22. Bashaiwoldu AB, Podczeck F, Newton JM (2004) The application of non-contact laser profilometry to the determination of permanent structural changes induced by compaction of pellets I. Pellets of different composition. Eur J Pharmaceut Sci 22, 55-61. 